\title{
Listening and communication styles in nursing students
}

\author{
Lisa McKenna ${ }^{1}$, Ted Brown ${ }^{2}$, Malcolm Boyle ${ }^{3}$, Brett Williams ${ }^{3}$, Claire Palermo ${ }^{4}$, Elizabeth Molloy ${ }^{5}$ \\ 1. School of Nursing and Midwifery, Monash University, Australia. 2. Department of Occupational Therapy, Monash \\ University, Australia. 3. Department of Community Emergency Health and Paramedic Practice, Monash University, \\ Australia. 4. Southern Clinical School, Monash University, Australia. 5. HealthPEER, Monash University, Australia.
}

Correspondence: Lisa McKenna. Address: School of Nursing and Midwifery, Monash University, Australia.

Email: lisa.mckenna@monash.edu

Received: May 2, 2014

Accepted: August 19, 2014

Online Published: September 9, 2014

DOI : 10.5430/jnep.v4n11p50

URL: http://dx.doi.org/10.5430/jnep.v4n11p50

\section{Abstract}

Objective: In nursing, where communication is crucial for collaboration with colleagues, informing and reassuring clients as well as advocating. Use of appropriate styles is fundamental. Consideration of nursing students' listening and communication styles is necessary to understand whether this area needs further enhancement in the curriculum. Yet, little information exists for nurse educators around this area.

Methods: A cross-sectional study of Bachelor of Nursing students from one Australian university was conducted using paper-based versions of the Listening Styles Profile (LSP) and Communicator Style Measure (CSM). Findings revealed strong preference for 'People' listening style and 'Friendly' communicator style.

Results: There were no significant differences between students across different stages of the course and only slight differences in preferences between genders. Preferences indicate appropriate communication for nursing, indicating underlying concern for the welfare of others.

Conclusions: Results suggest that participants' education had no effect on their preferences and may provide some information for educators aiming to develop such skills. Longitudinal studies of these attributes into the graduate year are recommended.

\section{Key words}

Communication, Education, Listening, Nursing student

\section{I ntroduction}

Communication with patients, their families and colleagues is an important part of being an effective nurse. Communication, however, is a complex process and people have different ways of communicating. The use of appropriate communication styles has many benefits in the provision of healthcare. Studies have shown a correlation between how health professionals listen and communicate and patient satisfaction, health outcomes and consequently the risk of attracting malpractice litigation ${ }^{[1-3]}$.

Communication is fundamental to effective nursing practice in developing therapeutic relationships, communicating with clients, groups and other health professionals, while also advocating for patients. The assumption that communication 
between patients and nurses who care for them is fundamental and articulated in Australian Competency Standards for the Registered Nurse ${ }^{[4]}$. According to Berlo ${ }^{[5]}$, the communication process entails three key components: a source (encoder), a message and a receiver (decoder). To successfully relate with patients, nurses need to be able to receive and decode information effectively, exhibiting different types of communication in different nursing contexts through visual, auditory and kinesthetic modes in order to ensure that the patients' concerns are addressed ${ }^{[6]}$. This leads to the assumption that nursing students need to be cognisant of different communication styles and approaches to suit different situations as part of their professional education.

Effective communication cannot exist without first listening to the patient, then conveying the necessary information rests on the nurse's ability to communicate. While communication is normally a two-way process, the unequal relationship, particularly in a hospital setting, puts the onus on the nurse to ensure patients are informed and, where necessary, feeling comforted about their situation. The use of appropriate styles of communication also facilitates collaboration with colleagues and, in extreme cases, poor communication been linked to deaths of patients ${ }^{[7,8]}$. Effective nurse-doctor communication has been directly implicated in the maintenance of patient safety ${ }^{[9,10]}$. It is argued that such communication is further complicated in nursing with increased casualisation of the nursing workforce ${ }^{[1]}$.

The action of listening is fundamental to effective therapeutic communication. Norton ${ }^{[12]}$ described a number of different communication styles, such as dominant, relaxed, argumentative, friendly and flexible. Yet despite being so important to practice, it has been argued that this area has been poorly explored in nursing when compared to other skills. Effective

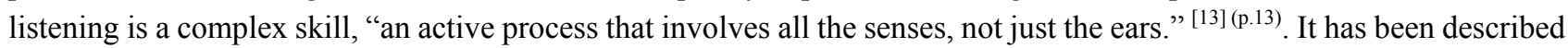
as a deliberate action that requires conscious engagement, listener silence, acknowledgement of verbal and nonverbal cues and respect ${ }^{[14]}$. A study by Kagan ${ }^{[15]}$ explored the concept of being listened to in ten adults in the U.S.A. She found that being listened to was important for participants' quality of life, resulting in feelings of being acknowledged, valued, and empowered. Yet, despite its importance, little research has focused on this aspect of nursing practice ${ }^{[14,16]}$. This lack of research limits the availability of guidelines for educators on how best to present content to nursing students and how best development of these skills can be facilitated. Hence, little evidence exists that can assist nurse educators in assisting students with development of these attributes.

The Listening Styles Profile (LSP) was employed for this study in order to examine listening styles ${ }^{[17]}$. This tool measures four different listening styles, that is, People, Action, Content and Time. Research suggests that most people have preference for a particular combination of styles. This preferred style is often related to habit rather than adopting the most appropriate style for the particular situation ${ }^{[17]}$. Awareness and concern for others' feelings characterises the 'People' style. Desire for preciseness, and frustration with disorganised presentations tends to characterise the 'Action' style. Those who prefer to closely consider facts and details often adopt a 'Content' listening style. Finally, those who are time conscious in the process of listening tend to favour the 'Time' style ${ }^{[17]}$.

In broadly considering communication, participants' preferred styles of communication were measured using the Communicator Styles Measure (CSM) ${ }^{[12]}$. The CSM measures for ten different communication styles. Norton describes these as "the way one verbally and paraverbally interacts to signal how literal meaning should be taken, interpreted, filtered, or understood" ${ }^{(\mathrm{p} .99)}$. Within this measure, ten styles are described. The 'Dominate' communicator has a tendency to want to take control of conversations. The 'Dramatic' communicator often exaggerates, understates or stylises one's conversation. Being argumentative is encapsulated in the 'Contentious' style. The 'Animated style' involves using non-verbal, physical cues, such as the use of nodding or hand gesturing. 'Attentive' style involves indicating that the conversation partner knows they are being listened to. Those able to leave memories employ the 'Impression Leaving' communication style. The 'Relaxed' style employs lack of anxiety during communication. 'Open' style involves being approachable reflecting affable, unreserved, extraverted characteristics. The 'Friendly' style ranges from avoiding hostility through to intimacy. Finally the 'Precise' style focuses on accuracy and the detail contained within the conversation. 
The importance of listening and communication in clinical practice makes it necessary to consider these skills in the education of nurses. Currently, specific teaching of communication occurs in the first semester of the course, then is imbedded within nursing practice throughout the remainder of the course, although not explicitly. The study sought to determine preferred listening and communication styles of undergraduate Bachelor of Nursing students and whether their styles changed over the duration of their course. Underpinning the study were the assumptions that firstly, communication between patients and nurses who care for them is fundamental. Secondly, nurses need to exhibit different types of communication in different nursing contexts. Finally, nursing students need to be cognisant of different communication styles and approaches to suit different situations of their professional education.

\section{Methods}

For the study, a cross-sectional design was selected employing administration of paper-based versions of the Listening Styles Profile (LSP) and Communicator Style Measure (CSM) to a cohort of undergraduate nursing students. The LSP consists of 16 items rated across a 5-point Likert style scale ranging from 0 (never) to 4 (always). Constructs derived from the LSP contain scores ranging from 4 to 20. Higher scores indicate stronger preference for that particular listening style. The instrument has been found to possess sufficient internal consistency as measured by Cronbach's alpha for each of the four constructs: People $(\alpha=0.678)$, Action $(\alpha=0.662)$, Content $(\alpha=0.612)$ and Time $(\alpha=0.681)$. These are below the commonly accepted level of 0.80 ; however, as each construct consists of only four items this was considered good internal consistency and is similar to what has been reported elsewhere ${ }^{[17-19]}$. In test-retest, the LSP was found to be stable over a two-week period ${ }^{[17]}$.

The Communicator Style Measure (CSM) is designed to assess ten styles of communication and a person's perception of their own communication ${ }^{[12]}$. The instrument consists of 51 items; however, when filler items and items related to communication image - which are not relevant to this study - were set aside, each communication construct consisted of four items. Each of these was rated on a 5 -point Likert style scale (YES! $=5$, yes $=4, ?=3$, no $=2, \mathrm{NO} !=1$ ), in which three items were reversed for analysis. CSM constructs have scores ranging from 4 to 20. Higher scores indicate stronger preference for the particular communication style. The CSM has sufficient internal consistency as measured by Cronbach's alpha for each of the constructs, that is, Friendly $(\alpha=0.603)$, Impression Leaving $(\alpha=0.681)$, Relaxed $(\alpha=$ $0.697)$, Contentious $(\alpha=0.667)$, Attentive $(\alpha=0.338)$, Precise $(\alpha=0.551)$, Animated $(\alpha=0.491)$, Dramatic $(\alpha=0.661)$, Open $(\alpha=0.572)$ and Dominate $(\alpha=0.740)$. Similar to the LSP, each construct in the CSM consists of four items and consequently alphas below the commonly accepted level of 0.8 are acceptable. The internal consistency for the constructs reported here are similar to those found in other studies to have used the CSM ${ }^{[20]}$.

All Bachelor of Nursing students enrolled at one campus of an Australian university were considered eligible to participate in this study. Prior to commencement of data collection, ethics approval was obtained from the university ethics committee. On conclusion of a scheduled lecture, one of the research team invited students to participate. Students were provided with an explanatory statement about the study, and informed that participation would be voluntary and anonymous. A research team member not directly involved in the students' academic program facilitated the process and participants were given a questionnaire that contained the LSP and CSM, along with a small number of demographic questions. The questionnaire took approximately fifteen minutes to complete and consent was implied by completion of the questionnaire.

The Statistical Package for Social Sciences (SPSS; Version 17.0) was used for data storage, tabulation, and generation of descriptive and inferential statistics. A measure of central tendency, median, has been used to summarise the construct results with descriptive statistics describing the demographic data. The results of both the LSP and CSM are ordinal data and hence not normally distributed. As such the non-parametric Kruskal-Wallis has been used to explore differences in preferences between participants enrolled in different year levels and age groups with the Mann-Whitney U tests used to examine gender variations. Results were considered statistically significant if the $p$ value was $<.05$. 


\section{Results}

\subsection{Demographics}

In total 200 nursing students participated in the study. There was strong representation of first year $(n=81)$ and third year $(\mathrm{n}=90)$ students and a weaker but still sufficient representation of second year students $(\mathrm{n}=29)$. Most participants were female $(90.5 \%)$ and were also either under 21 years of age (42.0\%), or between 21 and 25 years of age (29.0\%). This demographic profile reflects consistency with the actual demographic profile of students enrolled in the Bachelor of Nursing at the university.

\subsection{Listening styles}

LSP results are presented in Table 1. These indicate strongest preference for the 'People' style of listening. This was followed by moderate preference for 'Content' style. Little to no preference was shown for either 'Action' and 'Time' styles. Furthermore, there were no statistically significant differences between participants enrolled in each of the different year levels in the Bachelor of Nursing or their preference for any particular listening styles (see Table 2). There were also no statistically significant differences between the genders and their overall preferences (see Table 3 ).

\subsection{Communicator styles}

Results of the CSM are presented in Table 4. Preferences for most of the communicator styles were around the midpoint of the possible range between 4 and 20. Strongest preference was for the 'Friendly' style followed by 'Attentive' and 'Animated' styles. These participants showed lowest preference for the 'Contentious', 'Relaxed' and 'Dominant' styles. Overall there were minimal distinct differences in participants' preferences for particular communicator styles.

There were two constructs with statistically significant differences between participants enrolled in different year levels and their preference for any of the communicator styles. Fourth and first year students had less of a preference for impression leaving than second and third year students (see Table 5). Fourth year students had less of a preference for the precise style compare to other year students (see Table 5). The only other preference with a statistically significant difference was in the 'Precise' style between the genders with males more precise than females (see Table 6).

Table 1. Listening style preferences

\begin{tabular}{ll}
\hline Listening Style & Median \\
\hline People & 3.25 \\
Content & 2.25 \\
Action & 1.50 \\
Time & 1.50 \\
\hline
\end{tabular}

Table 2. LSP mean rank and year level differences

\begin{tabular}{llll}
\hline Listening style & Year & Mean Rank & $\boldsymbol{p}$ value \\
\hline \multirow{3}{*}{ People } & 1 & 100.25 & .572 \\
& 2 & 91.07 & \\
& 3 & 93.79 & .919 \\
Action & 4 & 138.0 & \\
& 1 & 95.78 & \\
& 2 & 97.05 & .151 \\
Content & 3 & 91.96 & \\
& 4 & 112.0 & \\
& 1 & 91.65 & .149 \\
Time & 2 & 102.36 & \\
& 3 & 93.97 & \\
& 4 & 14.5 & \\
\hline
\end{tabular}


Table 3. LSP mean rank and gender variation

\begin{tabular}{llll}
\hline Listening Style & Gender & Mean Rank & $\boldsymbol{p}$ value \\
\hline \multirow{2}{*}{ People } & Female & 95.05 & .256 \\
& Male & 110.47 & .589 \\
\multirow{2}{*}{ Action } & Female & 95.19 & .27 \\
\multirow{2}{*}{ Content } & Male & 87.97 & .27 \\
\multirow{2}{*}{ Time } & Female & 92.13 & .36 \\
\hline
\end{tabular}

Table 4. Communicator style preferences

\begin{tabular}{ll}
\hline Communication Style & Median \\
\hline Friendly & 16.0 \\
Attentive & 14.0 \\
Animated & 14.0 \\
Impression Leaving & 13.0 \\
Contentious & 12.0 \\
Precise & 12.0 \\
Dramatic & 12.0 \\
Open & 12.0 \\
Relaxed & 11.0 \\
Dominant & 11.0 \\
\hline
\end{tabular}

Table 5. CSM mean rank and year level differences

\begin{tabular}{|c|c|c|c|}
\hline Communication style & Year & Mean Rank & $p$ value \\
\hline \multirow{4}{*}{ Friendly } & 1 & 86.73 & \multirow{4}{*}{.798} \\
\hline & 2 & 2892.75 & \\
\hline & 3 & 93.69 & \\
\hline & 4 & 110.50 & \\
\hline \multirow{4}{*}{ Impression Leaving } & 1 & 78.59 & \multirow{4}{*}{.027} \\
\hline & 2 & 112.43 & \\
\hline & 3 & 93.58 & \\
\hline & 4 & 77.25 & \\
\hline \multirow{4}{*}{ Relaxed } & 1 & 97.95 & \multirow{4}{*}{.170} \\
\hline & 2 & 97.66 & \\
\hline & 3 & 80.45 & \\
\hline & 4 & 90.50 & \\
\hline \multirow{4}{*}{ Contentious/Argumentative } & 1 & 80.21 & \multirow{4}{*}{.144} \\
\hline & 2 & 99.68 & \\
\hline & 3 & 92.80 & \\
\hline & 4 & 137.00 & \\
\hline \multirow{4}{*}{ Attentive } & 1 & 81.22 & \multirow{4}{*}{.291} \\
\hline & 2 & 101.89 & \\
\hline & 3 & 92.17 & \\
\hline & 4 & 96.25 & \\
\hline \multirow{4}{*}{ Precise } & 1 & 80.04 & \multirow{4}{*}{.019} \\
\hline & 2 & 115.73 & \\
\hline & 3 & 88.86 & \\
\hline & 4 & 73.75 & \\
\hline \multirow{4}{*}{ Animated } & 1 & 80.24 & \multirow{4}{*}{.073} \\
\hline & 2 & 96.45 & \\
\hline & 3 & 95.49 & \\
\hline & 4 & 26.25 & \\
\hline \multirow{4}{*}{ Dramatic } & 1 & 81.03 & \multirow{4}{*}{.277} \\
\hline & 2 & 92.59 & \\
\hline & 3 & 95.40 & \\
\hline & 4 & 57.00 & \\
\hline \multirow{4}{*}{ Open } & 1 & 86.85 & \multirow{4}{*}{.407} \\
\hline & 2 & 103.02 & \\
\hline & 3 & 86.50 & \\
\hline & 4 & 64.50 & \\
\hline \multirow{4}{*}{ Dominant } & 1 & 83.51 & \multirow{4}{*}{.157} \\
\hline & 2 & 102.80 & \\
\hline & 3 & 83.10 & \\
\hline & 4 & 131.50 & \\
\hline \multirow{4}{*}{ Communicator Image } & 1 & 83.17 & \multirow{4}{*}{.206} \\
\hline & 2 & 107.00 & \\
\hline & 3 & 90.60 & \\
\hline & 4 & 112.00 & \\
\hline
\end{tabular}


Table 6. CSM mean rank and gender differences

\begin{tabular}{|c|c|c|c|}
\hline Communication style & Gender & Mean Rank & p value \\
\hline \multirow{2}{*}{ Friendly } & Female & 91.20 & \multirow{2}{*}{.875} \\
\hline & Male & 89.12 & \\
\hline \multirow{2}{*}{ Impression Leaving } & Female & 88.49 & \multirow{2}{*}{.105} \\
\hline & Male & 109.79 & \\
\hline \multirow{2}{*}{ Relaxed } & Female & 88.69 & \multirow{2}{*}{.293} \\
\hline & Male & 102.50 & \\
\hline \multirow{2}{*}{ Contentious/Argumentative } & Female & 89.28 & \multirow{2}{*}{.862} \\
\hline & Male & 91.56 & \\
\hline \multirow{2}{*}{ Attentive } & Female & 87.40 & \multirow{2}{*}{.091} \\
\hline & Male & 109.38 & \\
\hline \multirow{2}{*}{ Precise } & Female & 86.91 & \multirow{2}{*}{.037} \\
\hline & Male & 114.06 & \\
\hline \multirow{2}{*}{ Animated } & Female & 89.39 & \multirow{2}{*}{.755} \\
\hline & Male & 85.35 & \\
\hline \multirow{2}{*}{ Dramatic } & Female & 88.42 & \multirow{2}{*}{.642} \\
\hline & Male & 94.44 & \\
\hline \multirow{2}{*}{ Open } & Female & 88.49 & \multirow{2}{*}{.681} \\
\hline & Male & 93.82 & \\
\hline \multirow{2}{*}{ Dominant } & Female & 85.65 & \multirow{2}{*}{.282} \\
\hline & Male & 99.35 & \\
\hline \multirow{2}{*}{ Communicator Image } & Female & 89.97 & \multirow{2}{*}{.671} \\
\hline & Male & 95.59 & \\
\hline
\end{tabular}

\section{Discussion}

Effective listening and communication skills are fundamental to responsive, quality nursing care ${ }^{[14]}$. Previously however, little research had explored this aspect ${ }^{[14,16]}$ and little recent evidence exists to guide nurse educators in facilitating students to develop these attributes. This study has provided some insight into beginning to understand the ways in which undergraduate nursing students approach communication and listening. The results of the LSP showed that participants had strongest preference for the 'People' listening style which is characterised by interest or concern for the person to whom one is listening, and which is important in nursing. The 'Content' style, for which participants showed moderate preference, is characterised by interest in the detail of what a person is saying. These listening styles are well suited for the nursing profession. It should be noted that there are no right or wrong listening styles; however, different situations would benefit from different styles of listening. Furthermore, listening has been described as a function of habit ${ }^{[17]}$. Thus, the results showing these students were inclined to have an interest in the person to whom they are listening, and a focus on the details of what is being said, bodes well for when these students begin their career as a novice nurse. Furthermore, given that these listening styles are more a function of habit would suggest that these participants are likely to retain such preferences as they begin these careers.

No statistically significant differences were found between participants enrolled in different year levels and their listening styles preferences. This would suggest that their in class education and their clinical placement work has no effect on their listening styles. However, as this was a survey it provided a "snapshot" in time of the students' preferences to a specific style, which may have changed from an earlier style, and may change again in the future with ongoing exposure. It is possible that the transition from student to nurse could prompt changes in preferences as Kiewitz et al. ${ }^{[21]}$ suggest work pressures may have such impact. For instance, participants reported little to no preference for the 'Time' listening style. This style involves constant awareness of time whilst listening and may involve telling people how long they have to speak. When working on a busy ward where one's time is limited, it is plausible that a nurse would feel compelled to adopt a 
greater preference toward the 'Time' listening style. It is a recommendation for future study to assess whether transition from student to registered nurse is significant enough to prompt a change in preferences.

Results of the CSM corroborate the LSP results. Strongest preference amongst participants was for the 'Friendly' style. This style is characterised by amiability in how one interacts with others, which can range from a lack of hostility through to deep intimacy. In a profession such as nursing, one is expected to be friendly to patients and their family. As Welch ${ }^{\text {[22] }}$ stated, "even speed cannot compensate for rudeness, disrespect, or an uncaring attitude." ${ }^{(p .66)}$ The 'Friendly' preference was followed by moderate preferences for the 'Attentive' and 'Animated' styles. The 'Attentive' style involves reassuring the conversation partner that they are being heard, such as nodding while the other person speaks. The 'Animated' style is characterised through employing non-verbal cues, such as nodding and gesticulating. Norton ${ }^{[12]}$ considered many of the communication styles to cluster together, meaning that participants with a preference for one style would invariably also have a preference for another complementary communicator style. It has also been suggested that there is scope for interpretation of clusters. The results of this study support this notion as the 'Friendly' and 'Attentive' styles were preferred by most participants and are two styles Norton suggests cluster together. The strong preference across this cohort for the 'Animated' style potentially suggests this is another style that clusters well with the 'Friendly' and 'Attentive' styles.

Statistically significant differences were found between participants enrolled across different year levels of the Bachelor of Nursing in 'impression leaving' and 'precise' communication styles. The second year students had a greater preference for 'impression leaving "and being 'precise' compared to other years, especially fourth years who had the least preference for both constructs. It is possible that the participants' preferences will change when they make the transition from student to working professional; however, this transition would have to have a significant affect to overcome established communication habits. Despite this, there is evidence to suggest that effective communication in nursing does develop with experience ${ }^{[23]}$. The nature of how communication skills develop in graduates is an area that warrants further exploration.

There were only a small number of males in the cohort and overall their communicator style preferences were similar to those of the females. The only statistically significant difference reported was the males' greater preference for the 'Precise' style with there being a large mean rank difference (female mean rank 86.91 to male mean rank 114.06, $p=.036$ ). Overall the homogeneity in how males and females perceived themselves, in terms of communicator styles, is a finding that has been found a number of times in other studies ${ }^{[24,25]}$. Research, however, has found significant differences between perception and actual communication between males and females ${ }^{[25]}$. That is, the homogeneity of these results belies the actual differences in how males and females communicate.

It could be inferred that students enrolling in the Bachelor of Nursing have a disposition towards the 'People' listening style and moderate disposition towards the 'Content' style. The students also have a disposition towards the 'Friendly' style followed by 'Attentive' and 'Animated' communication styles. It cannot be said however, with certainty, that these students will retain these preferences during their course and when they begin working as a novice nurse.

The findings from this study will inform educators within the nursing program about how students perceive their listening and communication styles. These findings will assist educators to demonstrate modified listening and communications styles to suit specific nurse-patient, nurse-relative, and nurse-doctor situations in the simulation laboratories. It is anticipated that further work around this area will begin to address the paucity of evidence to guide nurse educators and curriculum developers to inform future curricula.

This study is potentially limited with the two measures used being self-report questionnaires, which measure stated intent and not actual behaviour. This does not invalidate the findings, as one's stated intent is a precursor to how they will actually behave. There is no concern that participants were dishonest in their answers as participation was voluntary, anonymous and not linked to any of their studies. In the worst case, the results of this study indicate how participants 
thought they should behave. Other potential limitations of this study relate to the sample and as such caution is recommended in generalising these results to other nursing students. This sample of students was drawn from one university in Australia and differences in curriculum and culture at other institutions may potentially have a significant impact on listening or communicator styles. The other limitation of the sample is that it was established using convenience sampling. As attendance is not taken at the end of lectures and refusals to participate were not counted, it is not possible to establish a response rate. The sample was large and the demographics do represent the actual demographic profile of students enrolled in the Bachelor of Nursing program such that it is believed this study is representative of the overall cohort of students in the course.

This study raises important implications for nursing and education. Listening and communication skills are core elements in effective caring relationships. Within such relationships, the ability to listen well cannot be understated. Recent criticisms of nursing education and the connection with quality of nursing care ${ }^{[26]}$ makes this study an important contribution. There is a need for nursing educators to apply evidence-based strategies that assist learners to develop sound communication, including listening, skills. They require resources that allow them to identify different listening styles and how to assess and develop these in learners. Furthermore, there is a need for more research that examines the nuances of communication in nursing and its application to education and practice.

Effective listening and communication are vital attributes for nurses. This study adds new understandings of these aspects in nursing. Participants in this study showed preference for a set of listening and communicator styles appropriate for nursing. The preferences that emerged indicate underlying interest and concern for others. The results also suggest that those people attracted to the nursing profession have a disposition toward these styles. Finally, education, both classroom and clinical placements, does not appear to have an effect on these preferences. It is not expected that the transition from study to the workplace would have effects on listening and communicator preferences. However, exploring the impact of this would be beneficial, ideally confirming this with a longitudinal study that tracks students across this transition.

\section{References}

[1] Street RL, Makoul G, Arora NK, Epstein RM. How does communication heal? Pathways linking clinician-patient communication to health outcomes. Patient Educ Couns. 2009; 74: 295-301. http://dx.doi.org/10.1016/j.pec.2008.11.015

[2] Meyer GS, Arnheim L. The power of two: Improving patient safety through better physician-patient communication. Fam Pract Manag. 2002; 9: 47-60. PMid:12221764

[3] Williams S, Weinman J, Dale J. Doctor-patient communication and patient satisfaction: a review. Fam Pract. 1998; 15: $480-492$. PMid:9848436

[4] Australian Nursing and Midwifery Council (ANMC). National Competency Standards for the Registered Nurse. (4th ed.). ANMC. Canberra; 2006.

[5] Berlo D. The Process of Communication: An Introduction to Theory and Practice. Holt Rinehart \& Winston, New York; 1960.

[6] Teutsch C. Patient-doctor communication. Med Clin North Am. 2003; 87: 1115-1145. http://dx.doi.org/10.1016/S0025-7125\%2803\%2900066-X

[7] Fiesta J. Communication - Are you listening? Nurs Manag. 1994; 25: 15-16.

[8] Van Ess Coeling H. Cukr PL. Communication styles that promote perceptions of collaboration, quality, and nurse satisfaction. J Nurs Care Qual. 2000; 14: 63-74. http://dx.doi.org/10.1097/00001786-200001000-00009

[9] Manojlovich M. Nurse/physician communication through a sensemaking lens: Shifting the paradigm to improve patient safety. Med Care. 2010; 48: 941-946. http://dx.doi.org/10.1097/MLR.0b013e3181eb31bd

[10] Robinson FP, Gorman G, Slimmer LW, Yudkowsky R. Perceptions of effective and ineffective nurse-physician communication in hospitals. Nurs Forum. 2010; 45: 206-216. http://dx.doi.org/10.1111/j.1744-6198.2010.00182.x

[11] Batch M, Barnard A, Windsor C. Who's talking? Communication and the casual/part time nurse: A literature review. Contemp Nurse. 2009; 33: 20-29. PMid:19715492 http://dx.doi.org/10.5172/conu.33.1.20

[12] Norton RW. Foundation of a communicator style construct. Hum Commun Res. 1978; 4: 99-112. http://dx.doi.org/10.1111/j.1468-2958.1978.tb00600.x 
[13] Stickley T, Freshwater D. The art of listening in the therapeutic relationship. Ment Health Pract. 2006; 9: 12-18. http://dx.doi.org/10.7748/mhp2006.02.9.5.12.c1899

[14] Shipley SD. Listening: A concept analysis. Nurs Forum. 2010; 45: 125-134. http://dx.doi.org/10.1111/j.1744-6198.2010.00174.x

[15] Kagan PN. Feeling listened to: A lived experience of human becoming. Nurs Sci Q. 2008; 21: 59-67. PMid:18096987 http://dx.doi.org/10.1177/0894318407310779

[16] Kagan PN. Listening: Selected perspectives in theory and practice. Nurs Sci Q. 2008; 21: 105-110. PMid:19023924 http://dx.doi.org/10.1177/0894318408315027

[17] Watson KW, Barker LL, Weaver III JB. The Listening Styles Profile (LSP-16): Development and Validation of an Instrument to Assess Four Listening Styles. Int J Listening. 1995; 9: 1-13. http://dx.doi.org/10.1080/10904018.1995.10499138

[18] Bodie GD, Villaume WA. Aspects of receiving information: The relationship between listening preferences, communication apprehension, receiver apprehension, and communicator style. Int J Listening. 2003; 17: 47-67. http://dx.doi.org/10.1080/10904018.2003.10499055

[19] Worthington DL. Exploring the relationship between listening style and need for cognition. Int J Listening. 2008 ; 22 : 46-58. http://dx.doi.org/10.1080/10904010701802154

[20] Graham EE. Communicator Style Measure. In R. B. Rubin, P. Palmgreen \& H. E. Sypher (Eds.), Communication Research Measures: A Sourcebook. Lawrence Erlbaum Associates, Inc., Mahwah; 2004.

[21] Kiewitz C, Weaver III JB, Brosius H-B, Weimann G. Cultural differences in listening style preferences: A comparison of young adults in Germany, Israel, and the United States. Int J Pub Opinion Res. 1997; 9: 233-247. http://dx.doi.org/10.1093/ijpor/9.3.233

[22] Welch SJ. Twenty years of patient satisfaction research applied to the emergency department: A qualitative review. Am J Med Qual. 2010; 25: 64-72. http://dx.doi.org/10.1177/1062860609352536

[23] Haley JE. Experience shown to affect communication skills of nurse case managers. Care Manag J. 2007 ; 8: 50-57. PMid:17595922 http://dx.doi.org/10.1891/152109807780845582

[24] Gudykunst WB, Lim, T-S. Ethnicity, sex, and self perceptions of communicator style. Commun Res Rep. 1985 ; 2: 68-75.

[25] Staley CC, Cohen JL. Communicator style and social style: Similarities and differences between the sexes. Commun Q. 1988; 36: 192-202. http://dx.doi.org/10.1080/01463378809369722

[26] Darbyshire P, McKenna L. Nursing's crisis of care: What part does nursing education own? Nurs Educ. 2013; 33: $305-307$. PMid:23531418 http://dx.doi.org/10.1016/j.nedt.2013.03.002 